\title{
ARTICLE
}

\section{How does psychotherapy work? The self and its disorders ${ }^{\dagger}$}

\author{
Gwen Adshead \& Peter Fonagy
}

\begin{abstract}
Gwen Adshead is a consultant forensic psychotherapist at Broadmoor Hospital. Peter Fonagy is Freud Memorial Professor of Psychoanalysis and Head of the Research Department of Clinical, Educational and Health Psychology, University College London.

Correspondence DrGwen

Adshead, Broadmoor Hospital, Crowthorne, Berkshire RG45 7EG.

Email: gwen.adshead@wlmht.nhs.uk
\end{abstract}

${ }^{\dagger}$ This is the first of two articles by Peter Fonagy and Gwen Ashead that consider the role of psychotherapy as an effective treatment for psychiatric disorders, focusing on mentalisation. The second, 'How mentalisation changes the mind', will be published in the September issue of Advances.

\section{SUMMARY}

There is now extensive evidence that different types of psychological therapy are effective for various psychiatric disorders, both in terms of symptom reduction and in improving the patient's capacity to function adaptively. In two articles, we set out some current ideas of how psychological therapies might 'work', drawing on neurobiological studies of brain plasticity and therapeutic efficacy. In this first article, we review the evidence that disorders of self-experience are common to many psychiatric disorders, and that psychological therapies 'work' on those disorders. The second article will appear in the next issue of Advances.

\section{DECLARATION OF INTEREST}

None.

Modern man (and woman) has been called 'Homo psychologicus' (Humphrey 1984): one who takes the experience of the self seriously. Historically, the self was understood principally in terms of its relationship with the body or with a divine creator, and the experiences of the self were described in stories, poems, songs and drama. However, the 19 th century saw the self, and its disorders, become the object of medical discourse, which facilitated the development of psychological treatments.

Since the 20th century, pharmacological treatment of mental disorders has been expanding at an enormous rate, especially from the 1950s onwards (Herzberg 2008). However, the number of people who are referred for psychological therapies also continues to increase (Olfson 2002). In the UK, governmental policy has supported Improving Access to Psychological Therapies (IAPT). At the same time, senior psychotherapist posts are being abolished by local services on the grounds that long-term psychotherapies are not costeffective compared with brief interventions that can be delivered by professionals who require less training (and therefore less pay).

In this first of two articles on psychological therapies, we draw on results from neuropsychiatry and animal studies to suggest that a key reason for people seeking psychological therapy is an experience of a disordered 'self'. We review the evidence that disorders of the self are common in psychiatric disorders, and the evidence that there is a neuropsychiatric basis to the self and its disorders.

\section{Psychotherapy works on the brain}

A few years ago, Roth \& Fonagy (2004) reviewed the evidence for the efficacy of over 100 different types of psychological therapies. The review identified evidence suggesting that certain therapies work better for some populations and some disorders. For example, cognitive-behavioural therapy has been shown to be effective for anxiety, depression, eating disorders and some delusional symptoms. Behavioural therapy has been shown to be effective for persistent fear conditions (such as phobias or obsessive-compulsive disorder or OCD), addictions, and certain kinds of sexual dysfunction. Psychodynamic therapies have been shown to be effective for post-traumatic stress disorder and personality disorder, and there is evidence suggesting that they are effective in depression and eating disorders. Family work with a systemic orientation was shown to be particularly effective for eating disorders and antisocial behaviour in delinquents; and a more recent review of group therapies also found them to be effective for a variety of disorders, especially severe mood disorders (Blackmore 2009).

One way of summarising the results of that review is that, although comparative trials might disappoint in the extent to which they dictate 'what works for whom', the overview of this vast database of over 1000 studies indicates that most disorders are responsive to some kind of psychological therapy and that the therapy chosen needs to be the appropriate technique for the problem.

\section{Neuroimaging studies}

Improved neuroimaging has provided evidence that psychological therapies change brain function (see reviews by Liggan \& Kay (1999), Etkin et al (2005), Roffman et al (2005) and Linden (2006)). At least 27 studies have been conducted, 
using very different imaging modalities (including fludeoxyglucose positron emission tomography, single-photon emission computed tomography, functional magnetic resonance imaging and xenon-enhanced computed tomography) with patients presenting with a range of psychiatric diagnoses (including OCD, major depressive disorder, schizophrenia, phobias, post-traumatic stress disorder and personality disorder). The psychological therapies studied have included behavioural, cognitive-behavioural, interpersonal, group, cognitive rehabilitation, eye movement desensitisation and reprocessing (EMDR) and dynamic therapies. The areas of brain function shown to be altered by psychological therapies are listed in Table 1.

The evidence so far supports Roth $\&$ Fonagy's (2004) conclusions that most major modalities can be effective in producing change in certain groups of patients, but that different techniques probably operate on different parts of the neuronal system. Most neuroimaging research has involved study of cognitive-behavioural therapies for relatively discrete conditions, such as phobias or OCD, although Roffman and colleagues' review included studies of the effect of interpersonal reflective therapies (Roffman 2005). As yet there are no published imaging studies of the major therapeutic orientations, such as transferencefocused therapy or mentalisation-based treatment, that have been shown to be effective with more complex disorders, although reports of such studies are forthcoming.

The results of studies of the neuronal effect of psychological therapies are consistent with the increasing evidence of brain plasticity throughout life (Ramachandran 2000; Doidge 2008). Studies by Kandel $(1989,1999)$ demonstrated neuronal change after a change in memory status, i.e. that learning something new produced changes in synaptic function through a change in the expression of a gene for a synaptic peptide. It seems obvious that learning produces change in junior developing brains, but research such as that of Kandel and Ramachandran $\&$ Blakeslee

TABLE 1 Brain areas affected by psychological therapies

\begin{tabular}{|ll|}
\hline Therapy & Brain area \\
\hline Cognitive therapy & $\begin{array}{l}\text { Dorsal prefrontal cortex, medial } \\
\text { prefrontal cortex }\end{array}$ \\
\hline Reflective therapy & $\begin{array}{l}\text { Anterior cingulate cortex, } \\
\text { posterior cingulate cortex, } \\
\text { precuneate nucleus, insula }\end{array}$ \\
\hline Behavioural therapy & Amygdala \\
\hline
\end{tabular}

(2000), working with phantom limbs, suggest that plasticity is also present in adult brains. It may be harder, and take longer, but old dogs can learn new tricks, and their brains change when they do.

\section{Psychological distress and disorders of the self}

Patients who are referred to National Health Service psychotherapy services are often distressed and have significant levels of psychiatric morbidity (Chiesa 2007; Scott 2008). Compared with patients managed in primary care, they have more selfharming behaviours and delusional symptoms and are more likely to have diagnoses of personality disorder. They also show higher levels of risk than primary care patients (Barkham 2005).

What might these patients have in common? As yet there has been no satisfactory answer to this question, although almost all agree that the essential characteristics of diagnoses such as personality disorder are not well articulated by the DSM diagnostic categories (Dahl 2008). Phenomenologically, perhaps the most critical feature is the disturbed sense of identity frequently described in a range of personality disorders (e.g. Blatt 1988). Fuchs (2007) linked the failure of these patients to establish a coherent self-concept to something akin to a 'post-modernist' stance that they appear to adopt in their lives, switching from one present to the next, always totally identified with their present state of affect. Jorgensen (2006) has linked this identity disturbance to social, organisational and cultural factors rather than individual history or personality structure. We have argued that a dysfunction or deficit in a sense of agency or self-directedness is a critical aspect of these problems (Fonagy 2009), which has been consistently identified in empirical clinical studies (e.g. Bender 2007).

The self is, among other things, a neuropsychiatric phenomenon, which can be studied using neuroimaging methods. Neuroimaging studies have consistently supported the assumption that envisioning the mind of another is underpinned by the same brain systems as those that identify one's own thoughts and feelings (Lieberman 2007; Lombardo 2007; Uddin 2007; Dimaggio 2008). The common circuitry used in mentalising self and others may explain why it is that even the normally developing child will find it a struggle to acquire a sense of his own mind as separate and distinct from the minds of others, and can help us to understand the self-other confusions in disorders such as personality disorder, which may be associated with the disruption of these neural systems. 
BOX 1 Phenomenology of self-experience

- Different levels of complexity of thought: first-order thinking ('I am writing') second-order thinking ('I am wanting to write and think')

third-order thinking ('I am thinking about wanting to think and write')

- Memory and consistency of self-experience over time

- A theory of mind, including self-concept and selfrecognition, and other concept and other recognition

- Self in groups or social self

(Kircher 2000)

\section{The self and the brain}

Self-representation involves the reptilian brain, the limbic cortex and the neocortex, and the different disorders of the self can be linked with specific neuronal areas. Executive function is known to involve the lateral prefrontal cortex, and self-experience has also been linked to the medial prefrontal cortex. Self-recognition involves the right limbic, left prefrontal and superior temporal cortex; the left prefrontal cortex has also been identified as being involved in integration of experience and a sense of agency. Memory functions are complex and are functionally organised in different parts of the brain. Damage to hippocampal and temporal regions produces obvious memory abnormalities, but more subtle pathological processes (such as uncontrollable memories that intrude into present consciousness or non-conscious personal semantic memories that affect behaviour) may be generated by different and additional areas.

TABLE 2 Disorders of self-experience

\begin{tabular}{|c|c|}
\hline Domain of self-experience & Examples \\
\hline Disorders of thinking & $\begin{array}{l}\text { Rumination, cognitive distortion, delusions, obsessional } \\
\text { activity }\end{array}$ \\
\hline Disorders of memory & $\begin{array}{l}\text { Post-traumatic stress disorder, amnesias, borderline } \\
\text { states }\end{array}$ \\
\hline \multirow{4}{*}{$\begin{array}{l}\text { Impaired theory of mind and } \\
\text { self-recognition }\end{array}$} & Autism \\
\hline & $\begin{array}{l}\text { Disorders of consistency and integrity of the self (e.g. } \\
\text { borderline personality disorder) }\end{array}$ \\
\hline & $\begin{array}{l}\text { Disorders of the recognition of the bodily self (e.g. eating } \\
\text { disorders, Capgras syndrome, attacks on the body) }\end{array}$ \\
\hline & Disorders of self-esteem (e.g. after child maltreatment) \\
\hline Impaired social self & Avoidant, paranoid and antisocial personality \\
\hline \multirow[t]{2}{*}{ Impaired relational self } & $\begin{array}{l}\text { Dyadic problems leading to repetitive relationship } \\
\text { breakdown }\end{array}$ \\
\hline & Problems in parenting or caregiving relationships \\
\hline
\end{tabular}

Reviews of the neuroimaging literature suggest that two distinct neural networks are shared by self-knowing and knowing others (Lieberman 2007; Uddin 2007). The first system involves a more body-based, frontoparietal mirror-neuron system which is involved in understanding the multimodal embodied self (e.g. face and body recognition) and understanding others through motor-simulation mechanisms (Gallese 2004; Rizzolatti 2004). This suggests that a fundamental process that allows us to appreciate the actions and emotions of others involves the activation of the mirror-neuron system for actions and the activation of visceromotor centres for the understanding of affect. This is thought to be one of the key evolutionary mechanisms underpinning social empathy - knowing from the inside, as it were, how someone else feels. This is an implicit, automatic system, providing physical other-to-self and self-to-other mapping, which is involved in the immediate understanding (or misunderstanding) of self and others.

The second, the cortical midline system, which consists of the medial prefrontal cortex, the anterior cingulate cortex and the temporal parietal junction in the lateral parietal cortex (Lieberman 2007; Uddin 2007), appears to play a central role in this process. This system is less body based, and processes information about the self and others in more abstract and symbolic ways (Frith 2007; Uddin 2007). Importantly, unlike the frontoparietal system, it appears to be mainly shaped across development by interpersonal relationships.

Kircher \& David (2000) describe a phenomenology of self-experience (Box 1), which includes:

- different levels of thought (first-order thinking, second-order thinking about the first-order thoughts, and third-order thinking about the thinking process itself);

- memory and consistency of self over time;

- self-concept and self-recognition that involves having a theory of mind, not only of oneself, but by extension of others: this phenomenon has been widely studied in conditions such as autism and schizophrenia;

- self in groups or social self, which is a function of the evolutionary pressure on primates to have the capacity to make successful group attachments (Dunbar 2003).

\section{Disorders of the self}

This phenomenology of self-experience naturally suggests a phenomenology of disorders of selfexperience (Table 2). Although the manifestations of such disorders may be complex and multifaceted, 
one common thread across disorders of selfexperience might be that they all represent different types of failures in the mind's capacity to represent its own activities and contents. Manifestations of such failures might include disorders of thinking (including the classic thought disorder, which is manifest in speech made incoherent by odd words, grammar or syntax); disorders of memory; disorders of consistency and integrity of self (as commonly described in borderline personality disorder); disorders of self-concept and image (most notably found in eating disorders, but may also be one of the consequences of sexual abuse); and disorders of self-recognition (found in disorders such as Capgras syndrome, but may be one cause of self-harming behaviours). Disorders of a social or relational self may be localised to one form of relationship (usually intimate dyads) or may be more global (as is seen in antisocial personality disorder). All these instances have in common a confusion in the mind over the meaning, significance or value of its own activities.

There are other models of the self and personality which may be helpful when thinking about how change occurs in psychotherapy. McAdams (1996) describes three levels of mental organisation: the personality (which is a function of behavioural traits that are largely genetic and is comparatively stable); the self (which is individual and consists of values, beliefs and attitudes that can be modified); and identity (which is constructed in social narratives with others and therefore changes in relationships over time).

Duggan (2004) reviews the issue of change in personality and concludes similarly that there are some basic aspects of personality that do not change very much, but that characterological adaptations (McAdams' 'self') are amenable to change.

From a bioethical point of view, it may also be helpful to think of psychiatric disorders as disorders of autonomy of will, thought and action, which can have a disastrous effect on the capacity to function effectively, and produce subjective distress (Gillon 1985; Adshead 2008).

Last, proper attention needs to be given to the affective self, which regulates and modulates emotions and is clearly disordered in a number of psychiatric conditions (Taylor 1997; Panksepp 1998). A common characteristic of patients referred for psychotherapy is that they are in psychological pain, as a result of a variety of negative affects that are dysregulated and seem overwhelming. Psychological pain, like physical pain, is modulated through a complex system of neuronal pathways, involving the hippocampus, thalamus and neocortex.

\section{The self, mentalisation and its disorders}

The process by which images of self or newly accessible memories are practised, considered and reflected on, is one aspect of what is called mentalisation (Bateman 2004) or metacognition (Dimaggio 2011). A key aspect of this process is self-reflective function, which operates at a number of levels. People with low levels of reflective function think in concrete ways and make poorquality judgements about the mental states of both themselves and others. At even lower levels of reflective function, individuals cannot articulate their own self-experience at all, and other people's experiences are not real to them.

Mentalising is an aspect of self-regulation; it helps an individual make sense of what is in their own mind and the mind of others, and facilitates recognition of what is self and what is not. Mentalising is a function of affective arousal, and the capacity to maintain certain types of mentalisation depends on the individual's capacity to regulate arousal. This capacity, in turn, is affected by early attachment experiences and temperament that, as it were, 'set' the internal homeostatic regulator (Nolte 2011). It is important to emphasise that automatic mentalisation is ongoing at all times, and that it is both relationship and situation specific (Fonagy 2011). Thus, even the best mentalisers may have gaps or lapses in the process.

Advances in neuroscience, developmental, social and cognitive research, and accumulating clinical experience have enabled us (Fonagy 2009) to construct a more differentiated picture of mentalisation. This is based on four polarities (Box 2) which must be balanced appropriately to specific situations for mentalisation to be 'fit for purpose' (the interpersonal and self-organisational function for which it was designed).

\section{BOX 2 The four polarities of mentalisation}

1 Implicit or automatic $v$. explicit or controlled mentalisation (Satpute 2006)

2 Mentalisation based on external $v$. internal cues about the internal state of self and others (Lieberman 2007)

3 Cognitive $v$. affective mentalisation (Shamay-Tsoory 2008)

4 A balance between the two distinct neural networks: i self-knowing: located in the medial prefrontal cortex, the anterior cingulate cortex and the precuneus (Frith 2006, 2007)

ii other knowing: located in the frontoparietal mirrorneuron system (Rizzolatti 2006) 
Although the pattern of limitations in mentalising capacity may differ between individuals and across diagnostic conditions, we suggest that in most severe disorders which involve the personality, imbalanced mentalisation on one or other of the polarities mentioned in Box 2 would be evident in adults with clinical mental disorder. Mentalisation, as measured by reflective function, is low in patients with personality disorder, depression and severe mental illness (Levinson 2006; Levy 2006). Failure of the mentalisation process may be of childhood or adult onset, sustained or episodic, generalised or discrete to persons, situations or even topics. In all these contexts and levels, the imbalance may be mild or severe. Only rarely is mentalisation failure associated with threat, hostility or predatory activity.

\section{Why might poor mentalising arise?}

The answer is as complex as any 'final common pathway' in a neurodevelopmental process can be (Cicchetti 2006). We see mentalisation failure as the consequence of a series of risk events during development. Significant vulnerability risk factors will include the early attachment environment and the availability of a caregiver with an interest in the infant's mental state, who through marked mirroring will establish robust self-state representations in the infant (Fonagy 2002). This process is of course moderated by constitutional factors such as infant temperament: an infant who is dominated by negative affect will be harder to respond to sensitively with the activation of the attachment system (Strathearn 2008) and will be less likely to elicit peripheral oxytocin (Strathearn 2009), which is known to enhance sensitivity to internal states (Domes 2007) and facial cues (Guastella 2008).

\section{Adverse experiences}

Adverse early experiences (which might include experiences of neglect, hostility, chronic fear, abandonment or actual pain infliction) result in a developmental environment which fails to stimulate proper dendritic growth or hyperstimulates growth in immature neuronal networks in the executive cortex (Leckman 2004). There is evidence to suggest that mentalising failure associated with insecure attachment arises from subtle disorders of brain function. Ramachandran \& Blakeslee (2000) argue that poor mentalising function, as revealed in immature psychiatric defences, is associated with abnormal right brain function. Functional magnetic resonance imaging studies of adults with insecure attachment show different patterns of activation compared with secure adults (Buchheim 2008; Vrticka 2008; Strathearn 2009). It is also possible that gene $\times$ environment interactions that increase the risk of developing psychiatric disorder are mediated by insecure attachment status (Caspers 2009).

\section{Risk factors}

The list of activating or provoking risk factors will undoubtedly include maltreatment, trauma and chronic stress, which undermine the language environment within which the child might acquire mentalisation (Lemche 2007; de Rosnay 2008). Their disruptive effects are maintained by mechanisms that can be more parsimoniously described in neurobiological terms, such as distortions in the functioning of arousal systems (Arnsten 1998; Mayes 2006), anomalous functioning of the prefrontal cortex (Cicchetti 2005) or even deficiencies in oxytocin levels (Heim 2008). Although an appropriate level of activation of the brain system mediating attachment appears to be both psychologically and biologically key to the development of mentalising (Fonagy 2007), imaging evidence and theorisation suggest that the hyperactivation of the attachment system undermines the capacity to think about mental states (Bartels 2004) (after all, love is known to be blind), along with other emotion-induced cognitive dysfunctions.

The so-called formation risk factors are likely to create the brain-behaviour environment within which mentalisation is difficult. The association between mentalisation, stress and attachment suggests that we should expect differences in the quality of mentalisation depending on the quality of the relationship within which it is observed (Allen 2008; Fonagy 2011). The specific condition which is likely to be triggered in the treatment of severe personality disorder is characterised by abnormally dense retrieval of negative memories and cognitions and an inhibition of judgements of social trustworthiness, paranoid thoughts and acute mentalising failure, as well as the reemergence of pre-mentalising forms of subjectivity that are typical of the toddler.

However, a number of interacting systems are involved in the deterioration of psychological capacities, making it hard to discern causal sequences. For example, mentalisation (understanding the intent behind one's own or others' reactions) can exert influence over affect regulation, especially negative affects, so adults whose mentalising is lacking in one of its components frequently also have poor control over negative feelings. Emotion dysregulation may also be a key reason for mentalising failure. Momentary failures 
of mentalising undermine a person's capacity to make good-quality inferences about the world and the other people in it, and this leads the person to find the world more stressful. This in turn means that they will be more prone to activate interpersonal schemata (or working models) that have been laid down and remain accessible as a result of the adverse childhood attachment experiences that contributed to the fragile establishment of mentalisation in the first place.

\section{Good mentalising}

There is a flip side to this and the almost infinite number of other vicious cycles which frequently occur in the minds of patients whose capacity to mentalise is vulnerable. This is that enhancing mentalisation can create a highly efficacious common pathway to 'cure' (or at least improvement). Just as there are many ways in which emotional arousal, stress and unsatisfactory interpersonal encounters can cause dramatic failures of mentalisation, which in turn creates increasing emotional turbulence that places further limits on mentalising capacity, we can also see benign cycles where achieving good mentalisation of interpersonal situations results in a range of benefits (Box 3).

\section{Conclusions}

Mentalising is linked to general mental functioning in multiple ways, so much so that critics might suggest that it has become meaningless as a theoretical entity. However, if mentalisation is so well connected, this can provide us with a useful clinical heuristic: making it the focus of psychotherapeutic work is likely to have a positive impact, regardless of the intended aim of the therapeutic intervention or the modality, frame or context in which the therapy was intended to be conducted. In the next article (Fonagy 2012), we consider the process of change and how psychotherapy 'works' on the brain and mentalising function.

\section{B0X 3 Benefits of enhanced mentalisation}

- Enhanced emotion regulation

- Associated decreased anxiety about self-regulation

- Improved effortful control over maladaptive interpersonal schemata

- Improved behavioural coping strategies in troubled interpersonal encounters

- Limitation of the impact of negative self-experience by being able to take a third-person position

\section{References}

Adshead G (2008) Personal responsibility, abnormality and ethics: psychotherapy as moral understanding. Psychiatry 7: 225-7.

Allen J, Fonagy P, Bateman A (2008) Mentalizing in Clinical Practice. American Psychiatric Press.

Arnsten AFT (1998) The biology of being frazzled. Science 280: 1711-2.

Barkham M, Gilbert N, Connell J, et al (2005) Suitability and utility of the CORE-OM and CORE-A for assessing severity of presenting problems in psychological therapy services based in primary and secondary care settings. British Journal of Psychiatry 186: 239-46.

Bartels A, Zeki S (2004) The neural correlates of maternal and romantic love. Neuroimage 21: 1155-66.

Bateman AW, Fonagy P (2004) Psychotherapy for Borderline Personality Disorder: Mentalization Based Treatment. Oxford University Press.

Bender DS, Skodol AE (2007) Borderline personality as a self-other representational disturbance. Journal of Personality Disorders 21: 500-17.

Blackmore C, Beecroft C, Parry G, et al (2009) Systematic Review of the Efficacy and Clinical Effectiveness of Group Analysis and Analytic/ Dynamic Group Psychotherapy. Centre for Psychological Services Research, School of Health and Related Research, University of Sheffield.

Blatt SJ, Auerbach JS (1988) Differential cognitive disturbances in three types of borderline patients. Journal of Personality Disorders 2 : $198-211$.

Buchheim A, Erk S, George C, et al (2008) Neural correlates of attachment trauma in borderline personality disorder: a functional magnetic resonance imaging study. Psychiatry Research 163: 223-35.

Caspers K, Paradiso S, Yucuis R, et al (2009) Association between the serotonin transporter promoter polymorphism (5HTTLPR) and adult unresolved attachment. Developmental Psychology 45: 64-76.

Chiesa M, Fonagy P, Bateman A (2007) Differences in clinical characteristics between patients assessed in specialist psychotherapy and primary care counselling. Psychological Psychotherapy 80: 591603

Cicchetti D, Curtis WJ (2005) An event-related potential study of the processing of affective facial expressions in young children who experienced maltreatment during the first year of life. Development and Psychopathology 17: 641-77.

Cicchetti D, Valentino K (2006) An ecological-transactional perspective on child maltreatment: failure of the average expectable environment and its influence on child development. In Developmental Psychopathology (2nd edn, vol. 3) (eds D Cicchetti, DJ Cohen): 129-201. John Wiley \& Sons.

Dahl AA (2008) Controversies in diagnosis, classification and treatment of borderline personality disorder. Current Opinion in Psychiatry 21: 78-83.

de Rosnay M, Harris PL, Pons F (2008) Making links between emotion understanding and developmental psychopathology in young children. In Social Cognition and Developmental Psychopathology (eds C Sharp, P Fonagy, I Goodyer): 343-86. Oxford University Press.

Dimaggio G, Lysaker PH, Carcione A, et al (2008) Know yourself and you shall know the other... to a certain extent: multiple paths of influence of self-reflection on mindreading. Consciousness and Cognition 17: 778-89

Dimaggio G, Nicolo G, Brune M, et al (2011) Mental state understanding in adult psychiatric disorders: impact on symptoms, social functioning and treatment. Psychiatric Research 190: 1-2

Doidge N (2008) The Brain that Changes Itself. Penguin.

Domes G, Heinrichs M, Michel A, et al (2007) Oxytocin improves 'mindreading' in humans. Biological Psychiatry 61: 731-3.

Duggan C (2004) Does personality change and, if so, what changes? Criminal Behaviour and Mental Health 14: 5-16. 


\section{MCO answers \\ 1 e $\quad 2$ e $\quad 3 d \quad 4 d \quad 5$ a}

Dunbar R (2003) The social brain: mind, language and society in evolutionary perspective. Annual Review Anthropology 32: 113-81.

Etkin A, Pittenger C, Polan HJ, et al (2005) Toward a neurobiology of psychotherapy: basic science and clinical applications. Journal of Neuropsychiatry and Clinical Neuroscience 17: 145-58.

Fonagy P, Gergely G, Jurist E, et al (2002) Affect Regulation, Mentalization and the Development of the Self. Other Press.

Fonagy P, Gergely G, Target M (2007) The parent-infant dyad and the construction of the subjective. Journal of Child Psychology and Psychiatry 48: 288-328.

Fonagy P, Luyten P (2009) A developmental, mentalization-based approach to the understanding and treatment of borderline personality disorder. Development and Psychopathology 21: 1355-81.

Fonagy $P$, Luyten $P$, Strathearn $L$ (2011) The roots of borderline personality disorder in infancy: a review of evidence from the standpoint of the mentalization based approach. Infant Mental Health Journal 32: 37-69.

Fonagy P, Ashead G (2012) How mentalisation changes the mind. Advances in Psychiatric Treatment 18: in press.

Frith CD, Frith U (2006) The neural basis of mentalizing. Neuron 50 $531-4$.

Frith CD (2007) The social brain? Philosophical Transactions of the Royal Society of London, Series B, Biological Sciences 362: 671-8.

Fuchs T (2007) Fragmented selves: temporality and identity in borderline personality disorder. Psychopathology 40: 379-87.

Gallese V, Keysers C, Rizzolatti G (2004) A unifying view of the basis of social cognition. Trends in Cognitive Sciences 8: 396-403.

Gillon R (1985) Autonomy and the principle of respect for autonomy. BMJ 290: 1806 .

Guastella AJ, Mitchell PB, Dadds MR (2008) Oxytocin increases gaze to the eye region of human faces. Biological Psychiatry 63: 3-5.

Heim C, Young LJ, Newport DJ, et al (2008) Lower CSF oxytocin concentrations in women with a history of childhood abuse. Molecular Psychiatry 14: 954-8.

Herzberg D (2008) Happy Pills in America: From Miltown to Prozac. Johns Hopkins University Press.

Humphrey N (1984) Consciousness Regained. Oxford University Press.

Jorgensen CR (2006) Disturbed sense of identity in borderline personality disorder. Journal of Personality Disorders 20: 618-44.

Kandel ER (1989) Genes, nerve cells, and the remembrance of things past. Journal of Neuropsychiatry and Clinical Neurosciences 1: 103-25.

Kandel ER (1999) Biology and the future of psychoanalysis: a new intellectual framework for psychiatry revisited. American Journal of Psychiatry 156: 505-24.

Kircher T, David A (2000) Self-consciousness: an integrative approach from philosophy, psychopathology and the neurosciences. In The Self in Neuroscience and Psychiatry (eds T Kircher, A David): 445-74. Cambridge University Press.

Leckman JF, Feldman R, Swain JE, et al (2004) Primary parental preoccupation: circuits, genes, and the crucial role of the environment. Journal of Neural Transmission 111: 753-71.

Lemche E, Kreppner MJ, Joraschky P, et al (2007) Attachment organization and the early development of internal state language: a longitudinal perspective. International Journal of Behavioral Development 31: 252-62.

Levinson A, Fonagy P (2006) Offending and attachment: the relationship between interpersonal awareness and offending in a prison population with psychiatric disorder. Canadian Journal of Psychoanalysis 12: 225-51.

Levy KN, Meehan KB, Kelly KM, et al (2006) Change in attachment patterns and reflective function in a randomized control trial of transference-focused psychotherapy for borderline personality disorder. Journal of Consulting and Clinical Psychology 74: 1027-40.

Lieberman MD (2007) Social cognitive neuroscience: a review of core processes. Annual Review of Psychology 58: 259-89.

Liggan D, Kay J (1999) Some neurobiological aspects of psychotherapy: a review. Journal of Psychotherapy Practice and Research 8: 103-14.

Linden DEJ (2006) How psychotherapy changes the brain: the contribution of functional neuroimaging. Molecular Psychotherapy 11: 528-38.

Lombardo MV, Barnes JL, Wheelwright SJ, et al (2007) Self-referential cognition and empathy in autism. Public Library of Science One 2: e883.

Nolte T, Guiney J, Fonagy P, et al (2011) Interpersonal stress regulation and the development of anxiety disorders: an attachment-based developmental framework. Frontiers in Behavioral Neuroscience 5 Sept): 55

Mayes LC (2006) Arousal regulation, emotional flexibility, medial amygdala function, and the impact of early experience: comments on the paper of Lewis et al. Annals of the New York Academy of Sciences 1094: 178-92.

McAdams D (1996) Personality, modernity and the storied self: a contemporary framework for studying the person. Psychological Inquiry 7: $295-321$.

Olfson M, Marcus SC, Weissman MM, et al (2002) National trends in the use of psychotropic medications by children. Journal of the American Academy of Child and Adolescent Psychiatry 41: 514-21.

Panksepp J (1998) Affective Neuroscience: The Foundations of Human and Animal Emotions. Oxford University Press.

Ramachandran VS, Blakeslee S (2000) Phantoms in the Brain. Fourth Estate.

Rizzolatti G, Craighero L (2004) The mirror-neuron system. Annual Reviews of Neuroscience 27: 169-92.

Rizzolatti G, Ferrari PF, Rozzi S, et al (2006) The inferior parietal lobule: where action becomes perception. Novartis Foundation Symposium 270: 129-40; discussion 140-125, 164-129.

Roffman JL, Marci CD, Glick DM, et al (2005) Neuroimaging and the functional neuroanatomy of psychotherapy. Psychological Medicine 35: $1385-98$.

Roth A, Fonagy P (2004) What Works for Whom? A Critical Review of Psychotherapy Research. Second Edition. Guilford Press.

Satpute AB, Lieberman MD (2006) Integrating automatic and controlled processes into neurocognitive models of social cognition. Brain Research 1079: 86-97.

Scott DJ, Nightingale A (2008) Outpatient dynamic psychotherapy services: an analysis of patient discharge data. Health Bulletin 58: 177-85

Shamay-Tsoory SG, Aharon-Peretz J, Perry D (2008) Two systems for empathy: a double dissociation between emotional and cognitive empathy in inferior frontal gyrus versus ventromedial prefrontal lesions. Brain 132 (Pt 3): 617-27.

Strathearn L, Li J, Fonagy P, et al (2008) What's in a smile? Maternal brain responses to infant facial cues. Pediatrics 122: 40-51.

Strathearn L, Fonagy P, Amico J, et al (2009) Adult attachment predicts maternal brain and oxytocin response to infant cues. Neuropsychopharmacology 34: 2655-66.

Taylor GJ, Bagby MR, Parker JPA (1997) Disorders of Affect Regulation: Alexithymia in Medical and Psychiatric IIIness. Cambridge University Press.

Uddin LQ, lacoboni M, Lange C, et al (2007) The self and social cognition: the role of cortical midline structures and mirror neurons. Trends in Cognitive Sciences 11: 153-7.

Vrticka P. Andersson F, Grandjean D, et al (2008) Individual attachment style modulates human amygdala and striatum activation during social appraisal. Public Library of Science One 3: e2868. 
MCQs

Select the single best option for each question stem

1 Psychological therapies:

a have been shown to be ineffective

b are all based on psychoanalytic theories of mind

$c$ are equally effective for all conditions

$\mathrm{d}$ do not work on the brain

e need to be matched to the appropriate condition.

\section{Patients referred to psychotherapy} services:

a are best described as 'the worried well'

b do not have significant psychiatric pathology

c rarely have personality disorder $\mathrm{d}$ are at less risk of harm than primary care patients

e may struggle with a disturbed sense of self.

3 The following brain areas have not been implicated in normal self-functioning:

a medial prefrontal cortex

b lateral prefrontal cortex

c insula

d occipital cortex

e anterior cingulate cortex.

4 Which of the following pairs of disorders is matched accurately with the disorder of self-experience?

a anorexia nervosa and disorders of thought

b $O C D$ and disintegration of self c schizophrenia and attacks on the body

d post-traumatic stress disorder and disorders of memory

e depression and thought insertion.

5 Enhanced mentalisation does not affect:

a cognitive performance

b arousal regulation

c affect regulation

d behavioural control

e the ability to take a third-person perspective. 